\title{
Unemployment and illegal drug use: concordant evidence from a prospective study and national trends
}

\author{
DAVID F PECK, MARTIN A PLANT
}

\begin{abstract}
Data from a previous study of 1036 young people in the Lothian region that indicated an association between unemployment and illegal drug use were examined in more depth to investigate the inter-relation between duration of unemployment and the use of illegal drugs, alcohol, and tobacco. After factors such as social class background and educational qualifications had been taken into account a weak but significant association was found between duration of unemployment and illegal drug use. No such association was found for alcohol or tobacco.

Similar results were obtained from an analysis of national statistics related to unemployment and illegal drug use. Both sets of data thus indicate that illegal drug use is moderately associated with unemployment.
\end{abstract}

\section{Introduction}

From $1979 / 80$ to 1983 a study was undertaken of the self reported alcohol, tobacco, and illicit drug use of a cohort of 1036 young people in the Lothian region. The subjects of this study were aged 15 to 16 at the beginning of the study and were followed up three to four years later. The study indicated that, though subjects who were unemployed during 1983 did not smoke or drink more heavily than other respondents, they had significantly more experience of illegal drugs such as cannabis, lysergic acid diethylamide (LSD), and opiates.

\footnotetext{
Alcohol Research Group, Department of Psychiatry, University of Edinburgh, Edinburgh EH10 5HF

DAVID F PECK, BA, DAP, senior lecturer

MARTIN A PLANT, MA, PHD, senior research fellow

Correspondence to: Dr Plant.
}

In this study we therefore investigated the relation between unemployment and illegal drug use in more detail by examining the inter-relation between duration of unemployment and the use of illegal drugs, alcohol, and tobacco. In a separate analysis national trends in unemployment were related to two indices of illegal drug use based on official statistics.

\section{Subjects and methods}

In 1979/80 baseline data were collected through a standardised questionnaire completed by 1036 respondents, aged 15 to 16 , in the Lothian region in groups of sizes ranging from 20 to 200 during school hours and under supervision by the researchers. During 1983 members of the entire study group were sought for follow up interviews. Fieldwork was undertaken by 28 trained interviewers, and data were elicited with a standardised schedule that took from 30 minutes to one hour to complete. Both the initial questionnaire and the follow up interview collected information on biographical details such as social class background, alcohol use, and tobacco and illegal drug use. The follow up interview also elicited information about educational qualifications, incomes, job histories, and unemployment. Additional details of the methodology used in the study have been given elsewhere. ${ }^{1-3}$

\section{Results}

\section{PROSPECTIVE STUDY IN THE LOTHIAN REGION}

Data collection-Baseline data were collected from 1036 respondents in 1979/80. During 1983, 957 (92\%) were reinterviewed. At both times specific items on the questionnaire were sometimes left unanswered. In 1979/80 the average number of people not answering a question about drugs was 36 (3.5\%), whereas the corresponding number for 1983 (largely owing to interviewers failing to record negative answers) was $43(4 \cdot 5 \%)$. We analyse here the data collected during 1983 and compare them with those obtained during 1979/80. The 1983 data related to 929 of the 957 people who were reinterviewed and from whom complete data were elicited about relevant drug use and employment. These 929 people constituted $89 \cdot 7 \%$ of the 
original study group of 1036 . The comparison of $1979 / 80$ and 1983 data (see table II) relates to 811 people who provided full responses during both collections of data to questions on drugs and also on their employment state during 1983 . These 811 people constituted $78.3 \%$ of the original study group or $84.7 \%$ of those reinterviewed in 1983 .

Unemployment and biographical traits-When reinterviewed during 1983, $12 \%$ of the original study group were either unemployed or taking part in the Youth Opportunities Programme. This was equivalent to $19 \cdot 2 \%$ of those who were economically active (excluding housewives and students). The modal duration of unemployment experienced by those who were unemployed at the time of reinterview was seven to 12 months for men and 13 to 24 months for women (table I). In addition, $136(36 \cdot 7 \%)$ of the 370 men and 157

TABLE I-Duration of unemployment experienced by respondents who were unemployed when reinterviewed during 1983

\begin{tabular}{lrc}
\hline \multirow{2}{*}{$\begin{array}{c}\text { Duration of unemployment } \\
\text { (months) }\end{array}$} & \multicolumn{2}{c}{ No of respondents } \\
\cline { 2 - 3 } & Men & Women \\
\hline$<1$ & 2 & 1 \\
$1-3$ & 10 & 8 \\
$4-6$ & 9 & 8 \\
$7-12$ & 26 & 13 \\
$13-24$ & 13 & 17 \\
$>24$ & 3 & 5 \\
\hline Total & 63 & 52 \\
\hline
\end{tabular}

$(35 \cdot 4 \%)$ of the 444 women who were currently employed reported having been unemployed at some time since leaving school. During July 1983 unemployment in the Lothian region, $12 \cdot 1 \%$, was the same as the average unemployment in Britain as a whole. ${ }^{4}$ The unemployment among young people in the United Kingdom, however, is higher than that among the overall labour force. In July $1983,23.4 \%$ of men and $16.9 \%$ of women aged 20 to 24 were unemployed. The corresponding figures for those aged 18 to 19 were $28.7 \%$ and $21 \cdot 6 \%$, respectively. ${ }^{5}$ Thus the study group showed a rather lower level of unemployment than that prevailing among their peers in the United Kingdom as a whole. The study group also differed from the overall population of comparable young people in the Lothian region; fewer respondents were married, and slightly more were from high socioeconomic backgrounds.

Illicit drug abuse and unemployment-At the ages of 19 and 20 unemployed men were significantly more likely than other men to report having used drugs. Women, however, did not differ significantly in this respect. The significant difference among men is striking because those who were unemployed had not differed significantly from the other men when data were first collected in 1979/80. Table II shows these results. Men who were unemployed when reinterviewed in 1983 were also significantly more likely than other men to report having used drugs such as LSD, heroin, and cocaine, which are classified under category A of the Misuse of Drugs Act $1971\left(\chi^{2}=12.62, \mathrm{df}=1, \mathrm{p}<0.001\right)$. Unemployed women did not differ from other women in this respect $\left(\chi^{2}=0 \cdot 16, \mathrm{df}=1, \mathrm{NS}\right)$. The duration of unemployment for respondents who were currently unemployed was weakly but positively associated with the number of illicit drugs ever used $n=+$ $0.27, p<0.001$ ) and with the number of drugs used that are classified under category A of the Misuse of Drugs Act $1971(\eta=+0 \cdot 16, p<0.05)$. To further clarify the apparent relation between duration of unemployment and illicit drug use an additional analysis by partial correlation was conducted. Partial correlation produces a coefficient that describes the relation between two variables while adjusting for the effects of one or more additional variables. ${ }^{6}$

TABLE II-Prevalence of admitted illicit drug use among unemployed respondents $1979 / 80$ to 1983

\begin{tabular}{|c|c|c|c|c|c|c|}
\hline \multirow[b]{2}{*}{ Year } & \multicolumn{2}{|c|}{$\begin{array}{l}\text { No (\%) of men using } \\
\text { illicit drugs }\end{array}$} & \multirow[b]{2}{*}{ Significance } & \multicolumn{2}{|c|}{$\begin{array}{l}\text { No (\%) of women using } \\
\text { illicit drugs }\end{array}$} & \multirow[b]{2}{*}{ Significance } \\
\hline & $\begin{array}{c}\text { Unemployed } \\
(n=49)\end{array}$ & $\begin{array}{c}\text { Others } \\
(n=331)\end{array}$ & & $\begin{array}{l}\text { Unemployed } \\
(n=34)\end{array}$ & $\begin{array}{c}\text { Others } \\
(n=397)\end{array}$ & \\
\hline $1979 / 80$ & $12(24 \cdot 5)$ & $53(16 \cdot 0)$ & $\begin{array}{c}\chi^{2}=2 \cdot 16 \\
\mathrm{df}=1 \\
\text { NS }\end{array}$ & $6(17 \cdot 6)$ & $49(12 \cdot 3)$ & $\begin{array}{c}\chi^{2}=0.39 \\
\mathrm{df}=1 \\
\mathrm{NS}\end{array}$ \\
\hline 1983 & $26(53 \cdot 1)$ & $113(34 \cdot 1)$ & $\begin{array}{c}\chi^{2}=5.80 \\
\mathrm{df}=1 \\
\mathrm{p}<0.02\end{array}$ & $12(35 \cdot 2)$ & $82(20 \cdot 7)$ & $\begin{array}{c}\chi^{2}=3 \cdot 12 \\
\mathrm{df}=1 \\
\mathrm{NS}\end{array}$ \\
\hline
\end{tabular}

In this analysis the possible confounding variables were respondents' social class background and educational qualifications. Social class was definet from the socioeconomic state of the head of each respondent's household determined from the standard classification of the Registrar General. The was still a significant but weak association between the number of illicit drugs ever used and duration of unemployment $(r=0 \cdot 25, p<0 \cdot 001)$.

Psychoactive drug use and incomes-Prices and incomes have been sug gested as important determinants of the use of psychoactive substances. ${ }^{3} \frac{78}{d}$ Moreover, it has been suggested that some young people in the United Kingdom do choose between legal and illegal drugs partly on the basis of their respective costs (P Rørstad, personal communication). Thorley ha further suggested that there may be a "hydraulic" relation between different drugs, whereby drug $B$ is substituted for drug $A$ if the price of drug $A$ 这 increased or its availability is curtailed (A Thorley, personal communicif tion). The relation between the disposable incomes and patterns psychoactive drug use of the study group were examined. This showed that as expected, incomes were weakly but positively correlated with the consumption of both alcohol $(\mathrm{r}=0.11, \mathrm{p}<0.001)$ and tobacco $(\mathrm{r}=0.1 £$ $\mathrm{p}<0.01$ ). In contrast, high disposable income was not significantly associ ted with illegal drug use $(r=-0.03, N S)$. This analysis was repeated for only unemployed respondents. Among these subjects neither alcohol nor tobacc $\varnothing$ use were significantly related to disposable income. Illicit drug use wast however, significantly and negatively associated with income $(r=-0 \cdot 16$ $\mathrm{p}<0.05$ ) but only to a modest degree.

\section{NATIONAL PATTERNS}

The results of the first study were obtained from a relatively small group im one part of the United Kingdom. To examine general patterns of association if any, between unemployment and illegal drug use some national data were compared. This comparison was based on annually published figures for the years 1970 to 1984 and relates to men and women in the United Kingdom as whole. The data examined were as follows:

(a) Average annual unemployment. From 1970 to 1984 this increase from $2 \cdot 6 \%$ to $13 \cdot 1 \%$. $^{9}$

(b) Cautions and convictions for offences concerning drug misuse. The data from 1970 to 1972 related only to convictions. These increased frop 9160 in 1970 to 25022 in $1984^{10}$ (Home Office, personal communication). o

(c) Narcotic drug addicts reported to be receiving notifiable drugs during treatment for their dependence at 31 December each year. These increased from 1426 in 1970 to 5869 in $1984 . .^{10}$ (Home Office, personal communica tion).

The figure shows the pattern of these three variables and indicates a clos association between unemployment and these two indicators of illegal drus use. The Pearson correlation coefficients for unemployment and drug cautions or convictions and addict notifications were 0.92 and 0.96 respectively. Both correlations were significant $(p<0.001)$. Whenever changes in two variables are measured simultaneously over time the correlation between them may be spuriously high. To measure these associations while controlling for the possible confounding effect of tim partial correlations were calculated. This analysis confirmed that unemploys

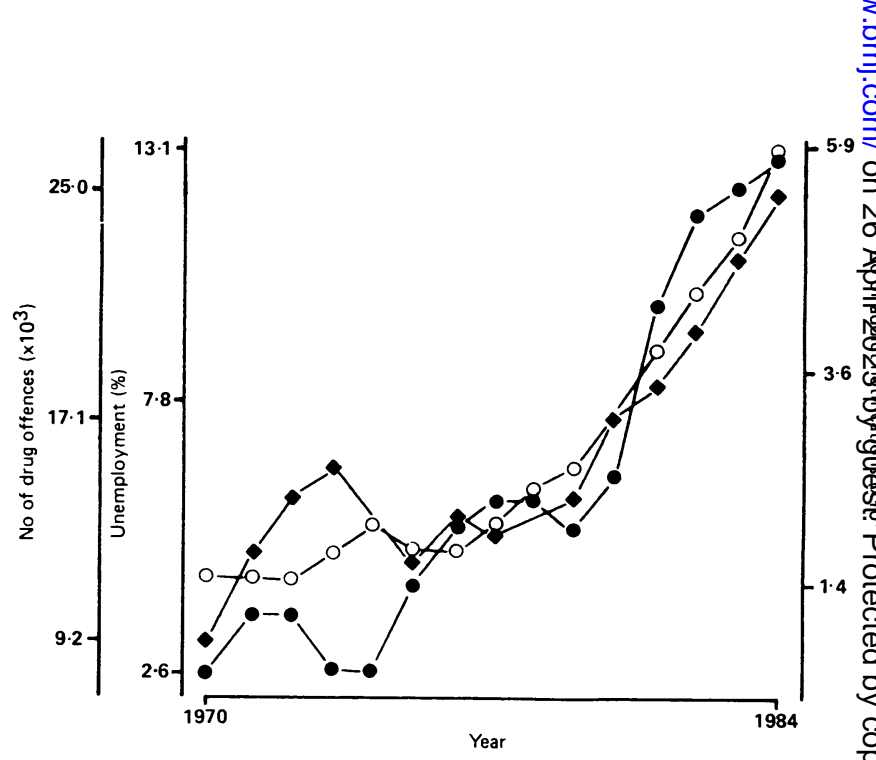

National unemployment, addict notifications, and drug offences, 1970 to 1984 $\Theta=$ Unemployment. $\mathrm{O}=$ Addict notifications. $\diamond=$ Drug offences. 
ment was significantly and positively correlated with drug misuse (drug cautions or convictions: $r=0.63, p<0.01$; addict notifications: $r=0.77$, $\mathrm{p}<0.001)$

\section{Discussion}

The two sets of data described above produced compatible results. Both indicate that illegal drug use is associated with unemployment. In contrast, the Lothian study indicated that alcohol and tobacco use are not positively linked with unemployment, ${ }^{3}$ a conclusion that is also supported by national data. Cigarette sales in the United Kingdom declined substantially between 1970 and 1984, and per caput alcohol consumption has also fallen since $1979^{112}$ (Tobacco Research Council, personal communication). As shown in the figure unemployment and the two selected indices of illegal drug use have increased sharply and in a strikingly similar manner during recent years.

Most of the British epidemiological studies of illicit drug use have been either cross sectional ${ }^{13-15}$ or have related to chronic or problem drug users in contact with treatment or supportive agencies. ${ }^{16-18}$ At present the Lothian study is the only prospective investigation in the United Kingdom to have elicited data about illicit drug use from a group of normal young people. Consequently, no directly comparable data are available and further investigations are needed to replicate or elaborate on this exercise.

Two major recent British cross sectional surveys have also noted an association between illicit drug use and unemployment. The first of these, the British Crime Survey, was conducted in 1981. This showed that self reported cannabis use among unemployed respondents in Britain as a whole (but not in Scotland) was significantly higher than that among other respondents. ${ }^{19}$

The second survey was carried out by Research International during 1985 to assess the impact of a publicity campaign on drugs commissioned by the Central Office of Information and the Department of Health and Social Security. This study indicated, through cluster analysis, that the subgroup of respondents at the highest risk of exposure to drugs was characterised by, among other factors, above average unemployment. ${ }^{20}$ Additional evidence was collected during 1985 by a survey of 212 young people attending youth clubs and centres in the London borough of Tower Hamlets. This indicated that self reported drug experience was far higher among those who were "compulsorily" unemployed than among other respondents (C Evans, unpublished findings).

Several British authors have noted a connection between illicit drug use and unemployment. Young stated that becoming a drug user was especially attractive to young people with little stake in the workaday world.$^{21}$ Plant noted that more contact with illicit drugs was particularly common among people of low status or who were unemployed. ${ }^{18}$ Wells and Stacey also concluded that regular users of cannabis were especially likely to be unemployed or to indulge in frequent job changing. ${ }^{22}$ Recent studies in the Wirral, the north of England, and Glasgow have indicated that the use of illicit drugs is, at least in part, a symptom of urban deprivation and unemployment. . $^{23-25}$

Several American studies have reached similar conclusions. Clayton and Voss, referring to Manhattan, concluded that among whites the highest proportion of self reported heroin use was evident among the unemployed..$^{26}$ Newmeyer and Johnson, referring to San Francisco, concluded: "Heroin use is perhaps related to unemployment. Thus the drastic rise in Bay Area unemployment during the late Johnston and early Nixon years provoked a rise in the use of heroin. The slow easing off of unemployment in 1971 and 1972 paralleled a drop in the number of new addicts. ${ }^{27}$ ",

Kandel, reviewing the use of marijuana, or cannabis, by a sample of 1325 young adults, noted that regular users of this drug were more likely than others to have left full time education and to experience frequent job changes. ${ }^{28}$ Avico et al, when screening Italian men being considered for drafting into the army, noted that opiate use was significantly more common among those who were unemployed than among other men..$^{29}$

Several authors have echoed Young's comments about the value of illicit drug use to those who lack conventional occupational status. Catton and Shain have advanced the following view of heroin use: "The sense of belonging to a group, the feeling of purpose and accomplishment and the sense of prestige are all important needs which this life appears to fulfil for the user. In the conventional world these needs are much harder to satisfy for the under-educated individual who has difficulty maintaining even a menial job. The life-style seems to be so important that some individuals feign addiction. ${ }^{30}$ " This view has been elaborated on by Sackman et al, who have suggested that drug use is a form of work, having similar social and psychological value to the protagonists as do legal forms of employment. ${ }^{31}$

Both sets of data discussed here are limited. The Lothian study related to a medium sized study group in only one area during a short period of time. In addition, the national data presented in the figure provide an imperfect measure of illegal drug use in the general population. They do, however, provide a useful indication of the trends of drug related problems. Many other indicators, such as drug related admissions to hospital and deaths, could also usefully be examined. A further complication is the alteration in the official definition of unemployment during recent years. Had the definition current in 1970 remained in force the increase in recent unemployment depicted in the figure would have been even steeper.

In spite of these qualifications the evidence reviewed above supports the conclusion that there is an association between illicit drug use and unemployment. Association does not necessarily impute a causal relation. Sometimes the adoption of certain patterns of drug use may render some people unemployable. ${ }^{19}{ }^{32}$ Sometimes unemployment may serve as a risk factor that increases the attractions of drug use and of the associated lifestyles. It would be naive to contend that unemployment is the only cause of illicit drug use. People use and abuse drugs for a perplexing and sometimes conflicting variety of reasons, and several reviews have noted the complex aetiology of psychoactive drug use. ${ }^{33-35}$

There is a clear link between illegal drug use and unemployment. Many possible explanations for this exist, but the most parsimonious conclusion is that high unemployment serves to foster drug use. This conclusion is consistent with a whole body of evidence from many studies conducted in different communities with different sampling techniques, data sources, and methodologies. Such consistency from disparate sources provides compelling support for the validity of this conclusion.

As indicated by Smith a considerable body of evidence connects unemployment with morbidity and mortality. ${ }^{36-38}$ Even so, it is often difficult to disentangle the influence of unemployment from that of a host of other social and economic factors that operate simultaneously and may also have an impact on health. Several authors have noted that illegal drug use, like alcohol and tobacco consumption, is influenced by economic factors. ${ }^{39}{ }^{40}$ It is notable that illegal drug use in the United Kingdom has been increasing at a time when both tobacco and, more recently, alcohol consumption have been decreasing. The relation between illegal drug use and legal drugs is unclear. One possible reason for increased illegal drug use is that the price of illegal drugs compared with that of alcohol and tobacco has declined. This may have enhanced the relative appeal of illegal drugs, especially to those on low incomes.

We recommend that in future policies to curb the use of alcohol and tobacco should be formulated on the basis of an awareness that illegal drugs may sometimes be used as substitutes for legal ones. The link found in this study suggests that illegal drug use may continue to proliferate in step with unemployment. Illegal drug use, once established, may prove to be a persistent legacy even if unemployment declines.

We acknowledge the help and support of Mrs Ray Stuart and Ms Elaine Samuel in conducting the Lothian prospective study. Mr John Duffy, of the Medical Research Council unit for epidemiological studies in psychiatry, and Mr Ralph McGuire, of the department of psychiatry, University of Edinburgh, are thanked for advice about statistical methods. This review was funded by the chief scientist office and criminological research group of the Scottish Home and Health Department, the Scotch Whisky Association, and the Medical Council on Alcoholism. 
References

1 Plant MA, Peck DF, Stuart R. Self-reported drinking habits and alcohol-related consequences amongst a cohort of Scotrish reenagers. Br $\mathcal{7}$ Addict 1982:77:75-90.

2 Plant MA, Peck DF, Stuart R. The correlates of serious alcohol-related consequences and illicit drug use amongst a cohort of Scottish teenagers. Br f Addict 1984;79:197-200.

Plant MA, Peck DF, Samuel E. Alcohol, drugs and school-leavers. London: Tavistock, 1985.

4 Manpower Services Commission. Labour market quarterly report (Scotland). Edinburgh: Manpower Services Commission, 1984

Peters M, ed. Department of Employment Gazette 1983;94:S37.

6 SPSS Inc. SPSSX user's guide. 2nd ed. New York: McGraw Hill, 1986:649.

Plant MA. Drugs in perspective. London: Hodder and Stoughton, 1981

Grant M, Plant MA, Williams A, eds. Economics and alcohol. London: Croom Helm, 1982.

Peters M, ed. Department of Employment Gazette. March 1975-February 1986.

10 Home Office. Statistics of the misuse of drugs in the UK, 1984. London: Home Office, 1985.

11 Lee PN, ed. Statistics of smoking in the United Kingdom. 7th ed. London: Tobacco Research Council, 1976

12 Produktschap Voor Gedistilleerde Dranken. Hoeveel alcoholhoudende dranken worden er in de wereld gedronken? Thurman C, adapter. London: Brewers' Society, 1986.

13 Hindmarch I. Patterns of drug use in a provincial university. Br $\mathcal{F}$ Addict 1970;64:395-402.

14 Plant MA. Drutakers in an English inen. London: Tavistock. 1975 .

14 Plant MA. Drugtakers in an English town. London: Tavistock, 1975.

16 Whodse AH. Drug dependent individuals dealt with by London asualty departments. Br Psychiatry 1977;131:273-80.

17 Stimson GV, Oppenheimer A. Heroin addiction. London: Tavistock, 1982.

18 Robertson JR. Drug users in contact with general practice. Br Med f 1985;290:31-2.

19 Mott HJ. Self-reported cannabis use in Great Britain in 1981. Br f Addict 1985;80:37-43.

20 Research International. Heroin misuse campaign evaluation. London: Research Bureau Ltd, 1986: appendix I

21 Young J. The drugtakers. London: Paladin, 1971

22 Wells B, Stacey B. A further comparison of cannabis (marijuana) users and non-users. Br f Addict $1976 ; 71: 161-5$
23 Parker H, Bakx K, Newcombe R. Drug use in Wirral: the first report of the Wirral misuse of drugs project. Liverpool: University of Liverpool, 1986

(24 Prorson G. Gilman M McIver S. Young people and heroin. London: Health Education Council 1986

25 Haw SC. Drug problems in greater Glasgow. London: Chameleon Press, 1985.

26 Clayton RR, Voss HL. Young men and drugs in Manhattan: a causal analysis. Rockville, Maryland: National Institute on Drug Abuse, 1981. (NIDA Research Monograph No 39 .)

27 Newmeyer JA, Johnson GR. The heroin epidemic in San Francisco: estimates of incidence and prevalence. Int $\mathcal{F}$ Addict 1976;11:417-8.

28 Kandel DB. Marijuana users in young adulthood. Arch Gen Psychiatry 1984;41:200-9.

29 Avico V, Pocchiari F, Zuccaro P, Donato L, Mariani F. Prevalence of opiate use among young men in Italy, 1980 and 1982. Bull Narc 1983;xxxv:63-71.

30 Catton $\mathrm{K}$, Shain $M$. Heroin users in the community: a review of the drug use and life-styles of addicts and users not in treatment. Addictive Diseases 1976;2:421-40.

31 Sackman BS, Sackman MM, de Angelis GG. Heroin addiction as an occupation: tradition addicts and heroin addicted polydrug users. Int $\mathcal{F}$ Addict 1978;13:427-41.

32 Blumberg $\mathrm{HH}$. British users of opiate-type drugs: a follow-up study. Br 7 Addict 1976;71:65-77.

33 Fazey C. The aetiology of psychoactive substance use. Paris: UNESCO, 1977.

Ple C. What aeviologe In Edwards G, Busch C, eds. Drug problens in Bricin. Lond Academic Press, 1981:245-80.

35 Peck DF. Some determining factors. In: Plant MA, ed. Drinking and problem drinking. London: Junction/Fourth Estate, 1982:65-83.

36 Smith R. "He never got over losing his job": death on the dole Br Med f 1985;291:1492-5.

37 Smith R. "I couldn't stand it any more": suicide and unemployment. Br Med f 1985;291:1563-6.

38 Smith R. "I'm not right": the physical health of the unemployed. Br Med f 1985;291:1626-9.

39 Bernard G. An economic analysis of the illicit drug market. Int f Addict 1983;18:681-700.

40 Lewis R, Hartnoll R, Bryer S, Daviaud E, Mitcheson M. Scoring smack: the illicit heroin marke in London. Br f Addict 1985;80:281-90.

(Accepted 28 fuly 1986)

\title{
Tropical Medicine
}

\section{Malaria prophylaxis: survey of the response of British travellers to prophylactic advice}

\author{
P A PHILLIPS-HOWARD, $M$ BLAZE, M HURN, D J BRADLEY
}

\begin{abstract}
A cohort study was conducted to determine the compliance of travellers with chemoprophylactic advice given over the telephone by the malaria reference advisory service. Travellers who visited their general practitioner first for advice about malaria prophylaxis were often advised to consult a specialist service themselves.

Compliance fell in travellers who were given complicated information and those who received conflicting advice when they contacted other advisory services. After returning to Britain $\mathbf{4 8 \%}$
\end{abstract}

\footnotetext{
Ross Institute and Department of Tropical Hygiene, London School of Hygiene and Tropical Medicine, London WC1 7HT

P A PHILLIPS-HOWARD, BSC, SRN, research fellow

M BLAZE, SRN, research assistant, malaria reference laboratory

$M$ HURN, research assistant, malaria reference laboratory

D J BRADLEY, FRCP, FRCPATH, professor of tropical hygiene

Correspondence to: Ms Phillips-Howard.
}

of the travellers reported that they were fully compliant with prophylactic advice; over a third of the travellers studied did not maintain prophylaxis on their return.

\section{Introduction}

The number of cases of imported malaria in Britain has risen from 101 cases in 1970 to 2212 in $1985 .{ }^{1}$ This increase is related to the expansion of the travel industry and to the resurgence of malaria owing to the resistance of malaria vectors to insecticides, poor management of control programmes, and the spread of strains of Plasmodium falciparum resistant to chloroquine and the newer alternative antimalarial combinations.

The prevention of malaria in travellers consists of drug prophylaxis and antimosquito measures to reduce exposure to mosquito bites. In the past 20 years new drugs have been introduced and new fixed or variable combinations of drugs have been recommended for prophylaxis as alternatives to chloroquine or proguanil. Advisory sources have often given conflicting advice as to which of these combinations provides the most effective prophylactic regimen-for example, one study found that 15 different prophylactic regimens were being taken in Dar es Salaam, Tanzania. ${ }^{2}$ Studies of specific groups of travellers have determined whether they sought advice ${ }^{3}$ and carried or took prophylactic drugs. ${ }^{46}$ No previous study has monitored travellers both before 